\title{
Impact of parthenium weed invasion on plants and their soil seedbank in a subtropical grassland, central Nepal
}

\author{
Jyoti Khatri-Chettri1 (iD, Maan Bahadur Rokaya ${ }^{2,3}$ (iD) and Bharat Babu Shrestha* (iD) \\ 'Central Department of Botany, Tribhuvan University, Kathmandu 44613, Nepal \\ ${ }^{2}$ Institute of Botany, The Czech Academy of Sciences, Zámek 1, 25243 Průhonice, Czech Republic \\ ${ }^{3}$ Global Change Research Institute, The Czech Academy of Sciences, Bělidla 986/4a, 60300 Brno, Czech Republic
}

\section{ARTICLE INFO}

Received October 19, 2021

Revised November 22, 2021

Accepted November 23, 2021

Published on January 14, 2022

*Corresponding author

Bharat Babu Shrestha

E-mail bb.shrestha@cdbtu.edu.np

Jyoti Khatri-Chettri's current affiliation is Trichandra Multiple Campus, Tribhuvan University, Kathmandu, Nepal.
Background: Parthenium hysterophorus L. (Asteraceae; hereafter Parthenium) is an invasive alien species of global significance because of its' negative ecological and socioeconomic impacts. This species is spreading rapidly from lowland Tarai to Middle Mountain regions in Nepal. In the present study, we analyzed the impacts of Parthenium on plant community composition including their soil seedbank in subtropical grasslands located in central Nepal. Data was collected in a $10 \mathrm{~m}$ long transects passing through areas of high (> $90 \%$ cover), medium (40\%-60\%) and low (<10\%) levels of Parthenium cover using a plot of $1 \mathrm{~m}^{2}$. Altogether, we sampled 90 plots in 30 transects. Seedling emergence method was used to estimate soil seedbank density in the soil samples $(0-10 \mathrm{~cm}$ depth) collected from the plots with high Parthenium cover.

Results: There was no significant difference in the plant species richness at different levels of Parthenium invasion whereas there was a significant change in the species composition of above ground flora due to Parthenium invasion. There was also a significant difference in species composition between soil seedbank and aboveground flora in the highly invaded plots. Parthenium was the most dominant in soil seedbank, contributing $65 \%$ to the total soil seedbank.

Conclusions: Our study suggests that Parthenium has considerable negative impact on the native grassland flora, and the dominance of Parthenium in the soil seedbank means there is a challenge for its management. It also suggests the need of monitoring the soil seedbank dynamics while managing Parthenium weed.

Keywords: grassland, germinable soil seedbank, species composition, Parthenium hysterophorus

\section{Introduction}

Increasing invasions by alien plants in grasslands and subsequent alteration of species composition and ecological processes is a global problem, particularly in the grasslands of human dominated landscapes (Cilliers et al. 2008; Seastedt and Pyšek 2011). Annual invasive weed Parthenium hysterophorus L. (Asteraceae; hereafter Parthenim), a native of Mexico, is one of the rapidly spreading invasive plant species found in grasslands and other ecosystems in tropical and subtropical regions of the Old World. It is already well established in $>45$ countries other than its native range (Maharjan et al. 2020; Mainali et al. 2015; Mao et al. 2021). It is an invasive weed of the global concern due to its' significant negative ecological and socio-economic impacts (Bajwa et al. 2016; Mao et al. 2021). Parthenium weed grows well in disturbed habitats such as the grasslands in urban and periurban areas, and various other natural habitats such as grassland, open woodlands, flood plains and river banks (Chhogyel et al. 2021; Gupta and Narayan 2006; Shrestha et al. 2019a; Tamado and Milberg 2000). High invasiveness of this weed has been attributed to its prolific seed production, persistent soil seedbank, intermediate $\mathrm{C}_{3}$ $\mathrm{C}_{4}$ mechanism of photosynthesis, high tolerance to abiotic stresses, and allelopathic potential (Bajwa et al. 2016). A typical mature Parthenium plant produces about 15000 seeds (Haseler 1976). It has been found that the large percentage of buried seeds of Parthenium can survive for one to several years (Butler 1984; Navie et al. 1998) and a study has reported that seeds of Parthenium can contribute up to $84 \%$ of the germinable soil seed bank (Ayele et al. 2013).

Parthenium weed is attributed in loss of crop and livestock production (Bajwa et al. 2019) and displacement of native flora (Hejda et al. 2017; Mollot et al. 2017) by modi- 
fying soil nutrients (Rokaya et al. 2020; Timsina et al. 2011). This often leads to the potential elimination of many useful forage plants and thus decrease pasture productivity (Navie et al. 1996). Additionally, Parthenium weed has a range of impacts on human health causing allergy, contact dermatitis, bronchitis, asthma and fever (Allan et al. 2019). A recent study in Africa has also shown that allelochemicals released from root of Parthenium can modulate oviposition behaviour and survivorship of malaria mosquito vector Anopheles gambiae (Milugo et al. 2021). Although a diversity of ecological and socio-economic impacts of this weed has been reported from different countries, there is geographic bias in studies. Most of the studies were undertaken in India, Australia and Pakistan (Maharjan et al. 2020). These are also the countries where national efforts to manage Parthenium weed is relatively high. One of the reasons for the low national efforts for the management of this weed could be due to inadequate empirical studies showing its impacts (Maharjan et al. 2020). As for example, Parthenium weed is already widespread in Nepal, but there are virtually no national efforts to control this weed (Shrestha et al. 2015; Shrestha et al. 2019a). Therefore, it is imperative to generate additional data on the impacts of this weed. This allows us to inform and encourage concerned national authorities to formulate appropriate management plan.

Previous studies in Nepal have revealed that Parthenium weed alters species composition of native plant species (Rokaya et al. 2020; Timsina et al. 2011), changes soil nutrient content (Timsina et al. 2011), causes health hazards to human (Shrestha et al. 2015), and affects peoples' livelihood and food security (Shrestha et al. 2019b). Although the impacts on aboveground vegetation have been examined, the impacts of Parthenium weed on soil seedbank remains much unexplored in Nepal, except a study by Rokaya et al. (2020) examining how soil seedbank changes over the time in highly invaded sites. As all plants growing in a particular area do not contribute to soil seedbank, examining the soil seedbank allows us to identify such plant species which contribute to soil seedbank (Coffin and Lauenroth 1989). Soil seedbank studies also suggests regeneration potential and future composition of the plant community, especially to those that rely mostly on non-vegetative means of reproduction. Comparing the species composition at different levels of Parthenium invasion helps to evaluate its exact and potential impacts on plant community composition. In the present study, we specifically answered following research questions: (1) Do plant species richness and composition vary among sites of the different levels of Parthenium invasions? (2) Is there any difference in species diversity (species richness and composition) between aboveground and below ground? (3) What is the extent of contribution of Parthenium to the soil seedbank? To answer above-mentioned questions, we sampled vegetation in low, medium and high Parthenium invaded sites, compared above ground and be- low ground plant species, and estimated germinable soil seedbank density in central Nepal.

\section{Materials and Methods}

\section{Study area}

The study area is located in the Siwalik region of Makawanpur district in south-central Nepal (Fig. 1). Geologically, the Siwalik region represents Sub-Himalayan zone (southernmost front of Himalaya sensu lato) with sandstone, siltstone, mudstone and boulder conglomerate (Upreti 1999). The area lies at the eastern part of the east-west oriented Chitwan Valley which is the largest inner Tarai Valley in central Nepal, and extends into Makawanpur, Chitwan and Nawalpur districts. The region receives monsoonal rainfall and has a dry subtropical climate with hot-humid summers (monsoon) and cold-dry winters. Annual rainfall is about $2430 \mathrm{~mm}$ (> 80\% during four monsoon months [June-September]) and mean temperature ranged from $14^{\circ} \mathrm{C}$ (January) to $28^{\circ} \mathrm{C}$ (June) (based on the weather data recorded at the nearest weather station Nepal Forestry Institute at Hetaunda; Marahatta et al. 2009). Sal (Shorea robusta) forest is the dominant vegetation of the Valley whereas small patches of tropical deciduous riverine forests, Dalbergia-Acacia forest, and riverine grasslands are also found in the Valley.

The sampling sites are located in Hetaunda Municipality which is the district headquarter and the most populated and urbanized city of Makawanpur district. The sampling sites $\left(27^{\circ} 25^{\prime} \mathrm{N}\right.$ latitude, $85^{\circ} 03^{\prime} \mathrm{E}$ longitude, $450-490 \mathrm{~m}$ asl elevation) were the grasslands located in the property of Hetaunda Cement Factory (two of the three sites) and Hetaunda Industrial Area (one of three sites) (Fig. 1). The grassland had been grazed throughout the year by domestic animals, and fodder collection activities were high during the summer. These sites were also subjected to frequent sport activities during winter months. Parthenium invasion was high at all sites with only a few Parthenium free patches. Other invasive weeds such as Lantana camara, Mesosphaerum suaveolens, Senna tora, among others, were also present in the study area.

\section{Vegetation and soil seedbank studies}

\section{Vegetation sampling}

The vegetation sampling was carried out during late monsoon season (September) along 30 transects of about $10 \mathrm{~m}$ long with 10 transects at each of the three sites. Along each transect, three plots of $1 \mathrm{~m} \times 1 \mathrm{~m}$ were sampled in such a way that they represented $>90 \%,>40 \%$ to $\leq 60 \%$ and $<10 \%$ cover of Parthenium, corresponding to high, medium and low levels of Parthenium invasion, respectively. During the sampling, vascular plant species rooted in plots were recorded to determine the plant species richness 

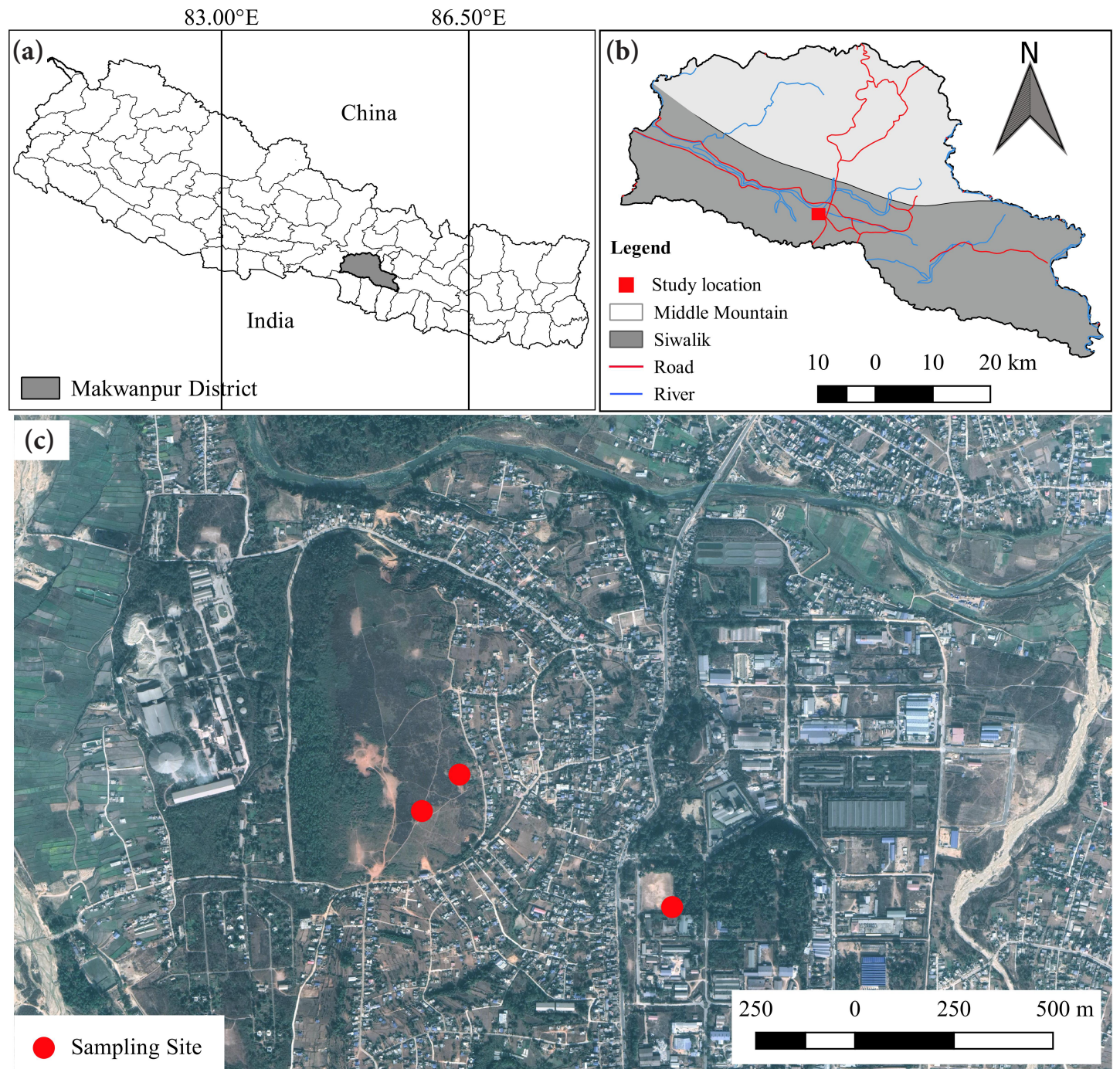

Fig. 1 Location of Makawanpur district in Nepal (a), the study location in Makawanpur district (b) and the sampling sites in the grasslands (c).

and composition. Numbers of Parthenium individuals were also recorded to determine Parthenium density. Maximum height of Parthenium and coverage of other plant species inside each plot were also recorded. After vegetation sampling, each plot with high level of Parthenium invasion was marked with wooden pegs for collecting soil samples in the next month to study soil seedbank.

\section{Soil collection for seedbank}

Soil samples were collected after one month of vegetation sampling (i.e., October) when most of the plants including Parthenium dispersed their seeds. They were collected from the plots having high (> 90\%) Parthenium coverage. For this, each plot was divided into four sub-plots $(50 \mathrm{~cm} \times$ $50 \mathrm{~cm}$ ) and soil sample was collected from one of these sub-plots selected randomly (lottery method). Prior to the soil collection, the aboveground vegetation and any plant debris (but not seeds) were removed. Soil samples were collected with the help of metallic soil core sampler (diameter $10 \mathrm{~cm}$ ). Soil was collected in two layers: from surface to 5 $\mathrm{cm}(0-50 \mathrm{~cm})$, and from 5 to $10 \mathrm{~cm}$ depths $(5-10 \mathrm{~cm})$. Altogether there were 60 soil samples collected from 30 plots.

\section{Seed germination}

Seedling emergence method was used to assess the germinable soil seedbank (Simpson 1989). This method has been also used previously for the study of soil seedbank of Parthenium weed (Ayele et al. 2013; Navie et al. 2004). Collected soil samples were observed for eight months in the greenhouse to determine the germinable soil seedbank. For this, earthen pots ( $15 \mathrm{~cm}$ diameter) were filled up to $2 / 3 \mathrm{rd}$ part with heat sterilized sand. Then soil sample was spread uniformly over the sand layer such that depth of the soil sample was $\leq 2 \mathrm{~cm}$. Sand and soil sample was separated by a paper to prevent their mixing. There were altogether 60 pots. Soil was maintained moist by regular watering. Number of seedlings of each species emerged in each pot was recorded weekly during first one month and in two weeks period during next seven months. In each observation, once Parthenium seedlings and other species were identi- 
fied they were removed to avoid crowding. Those species which could not be identified in vegetative stage were allowed to flower for proper identification.

\section{Plant collection, herbarium preparation and identification}

Specimens of all plant species encountered during vegetation sampling as well as those grown in green house, were collected, tagged, dried and then mounted on the herbarium sheets. They were identified with the help of local flora (e.g., Siwakoti and Varma 1999) and by comparing with the specimens housed at Tribhuvan University Central Herbarium (TUCH), Kirtipur and National Herbarium and Plant Laboratories (KATH), Godawari. We followed Roskov et al. (2019) for the nomenclature.

\section{Numerical analysis}

Community and population attributes recorded in plots with different intensity of Parthenium invasion were compared either by using one-way analysis of variance (ANOVA) or Krushkal-Wallis test depending on the nature of the data. None of the original data met the assumption of the homogeneity of variance. Variance became equal after species richness (number of species per plot) and Parthenium density were log transformed. Therefore, mean values of these attributes were compared among plots with different intensity of Parthenium invasions using ANOVA (using log transformed values) followed by Duncan homogeneity test. Other attributes (e.g., maximum height of the Parthenium, Parthenium cover, and other plant species cover) did not meet the assumption of equal variance even after transformation. Therefore, they were compared using non-parametric Kruskal-Wallis test followed by pair-wise Mann-Whitney U-test. These non-parametric tests use median values for significance test of difference. These statistical analyses were done using Statistical Package for Social Science (SPSS Inc., Chicago, IL, USA).

Germinable soil seedbank density (seeds $/ \mathrm{m}^{2}$ ) of Parthenium as well as other species were determined for two soil depths $(0-5 \mathrm{~cm}$ and 5-10 cm). Percentage contribution of Parthenium to total germinable soil seedbank was also cal- culated. Similarity Indices (Jaccard's and Sorenson's Similarity Indices) were calculated to assess the similarity of the species composition between aboveground vegetation and the corresponding soil seedbank following Zobel et al. (1987).

Multivariate tests were used for plant species composition in plots with different levels of Parthenium invasions and also to compare above ground flora and below ground soil seedbank flora. For the plots with different levels of Parthenium invasions, the gradient length was 2.68 and for the above ground and belowground flora, gradient length was 4.02. So, we used Canonical Correspondence Analysis (CCA) in both analyses (Šmilauer and Lepš 2014) by using Canoco 5.12 (terBraak and Šmilauer 2012). In CCA, model was built in the way to know associated plant species in low, medium and high invaded plots, and also above ground and below ground. The significance was tested by performing Monte Carlo permutation test $(n=4999)$ and we down weighted the rare species to reduce their effect on the results.

\section{Resullts}

\section{Species richness and composition at different levels of parthenium weed invasion}

We recorded a total of 62 plant species including Parthenium in the plots of high, medium and low levels of Parthenium invasions (Additional file 1: Table S1). Among them, 59 species were present in the plots with high Parthenium invasion, 48 species in the medium, and 48 species in the plots with low Parthenium invasion. There was no significant difference in the species richness among various levels of Parthenium invasion though Parthenium density, maximum height, cover of Parthenium, and other vegetation cover were considerably diverse at different levels of Parthenium invasion (Table 1).

The species composition in plots with different levels of Parthenium invasion were significantly different ( $p=$ 0.004, Fig. 2). Most plant species were recorded across all

Table 1 Community and population attributes measured in plots of the different levels of Parthenium invasion

\begin{tabular}{|c|c|c|c|c|c|c|}
\hline \multicolumn{2}{|c|}{ Attributes } & \multirow{2}{*}{$\begin{array}{c}\text { Species richness } \\
\left(\# \text { species } / \mathrm{m}^{2}\right)\end{array}$} & \multirow{2}{*}{$\begin{array}{c}\begin{array}{c}\text { Parthenium } \\
\text { density }\left(\text { stem } / \mathrm{m}^{2}\right)\end{array} \\
410^{c} \pm 122\end{array}$} & \multirow{2}{*}{$\begin{array}{c}\text { Max. height of } \\
\text { Parthenium }(\mathrm{cm}) \\
423^{c}(201)\end{array}$} & \multirow{2}{*}{$\begin{array}{c}\text { Parthenium } \\
\text { cover }(\%)\end{array}$} & \multirow{2}{*}{$\begin{array}{c}\text { Other vegetation } \\
\text { cover }(\%) \\
78^{\mathrm{b}}(30)\end{array}$} \\
\hline Levels of & High & & & & & \\
\hline Parthenium & Medium & $15^{\mathrm{a}} \pm 3$ & $126^{b} \pm 23$ & $147^{\mathrm{b}}(147)$ & $45^{b}(6)$ & $98^{\mathrm{a}}(6)$ \\
\hline invasions & Low & $14^{\mathrm{a}} \pm 4$ & $34^{a} \pm 6$ & $8^{a}(19)$ & $4^{\mathrm{a}}(4)$ & $100^{\mathrm{a}}(11)$ \\
\hline \multirow[t]{4}{*}{ Test statistics } & $\mathrm{F}$ & 1.68 & 106.89 & - & - & - \\
\hline & $\chi^{2}$ & - & - & 76.92 & 79.99 & 33.33 \\
\hline & Degree of freedom & 2,87 & 2,87 & 2 & 2 & 2 \\
\hline & $p$-value & 0.192 & $<0.001$ & $<0.001$ & $<0.001$ & $<0.001$ \\
\hline
\end{tabular}

Main entries for values of species richness and density of Parthenium are mean \pm standard deviation; values for other parameters are medians (interquartile range)

Attributes analyzed by ANOVA have their F values and those analyzed by Kruskal-Wallis test have chi-square $\left(\chi^{2}\right)$ values. Values within each column with different alphabets $\left({ }^{a},{ }^{b}, c\right)$ in superscripts are significantly different at $p<0.05$ 


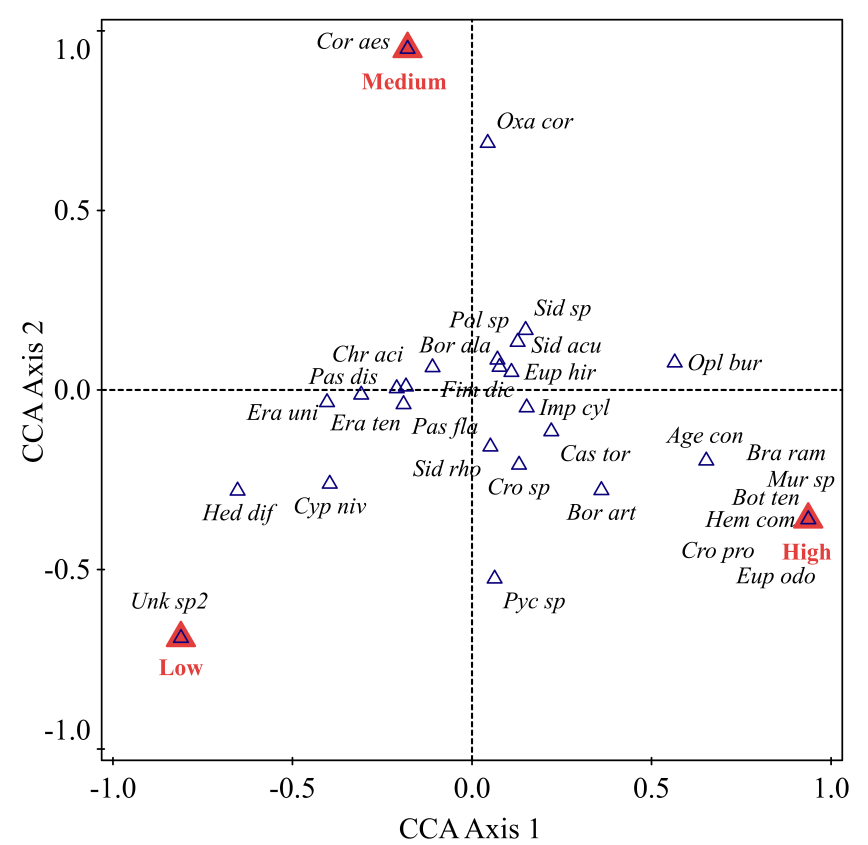

Fig. 2 Species composition in plots with different levels of Parthenium invasion. First Canonical Correspondence Analysis (CCA) axis explained $3.46 \%$ of variation and second axis $0.85 \%$. Full names of the species are in Additional file 1 (Table S1).

the plots. Few species such as Ageratum conyzoides, Brachiaria ramosa, Murdannia sp., Bothriospermum tenellum, Hemarthria compressa, and Crotalaria prostrata were strictly found in highly invaded plots whereas Oxalis corniculata and Corchorus aestuans were found in medium invaded plots.

\section{Comparison between above ground and belowground flora}

We recorded a total of 46 species in soil seedbank (Additional file 1: Table S2); 42 species were from top layer $(0-5 \mathrm{~cm}$ depth) and 25 species were from deeper layer $(5-10 \mathrm{~cm}$ depth). Jaccard's and Sorensen's Similarity Indices between standing (above ground) flora in the plots having high levels of Parthenium invasion and the corresponding soil seedbank (below ground) flora were $19 \%$ and $32 \%$, respectively.

The composition of associated plants varied significantly $(p=0.002)$ in between above ground flora and soil seedbank (below ground flora) with more plant species being reported from above ground (Fig. 3). Species such as Phyllanthus urinaria, Desmodium triflorum, Borreria alata, Polygala sp., Fimbristylis dichotoma, Chrysopogon aciculatus, Echinochloa colona, and Imperata cylindrica were found as above ground flora. Whereas, Carex sp., Phyllanthus sp., Oxalis corniculata, Bidens pilosa, Mecardonia procumbens, Ageratum sp., and Sonchus wightianus were strictly found as below ground flora.

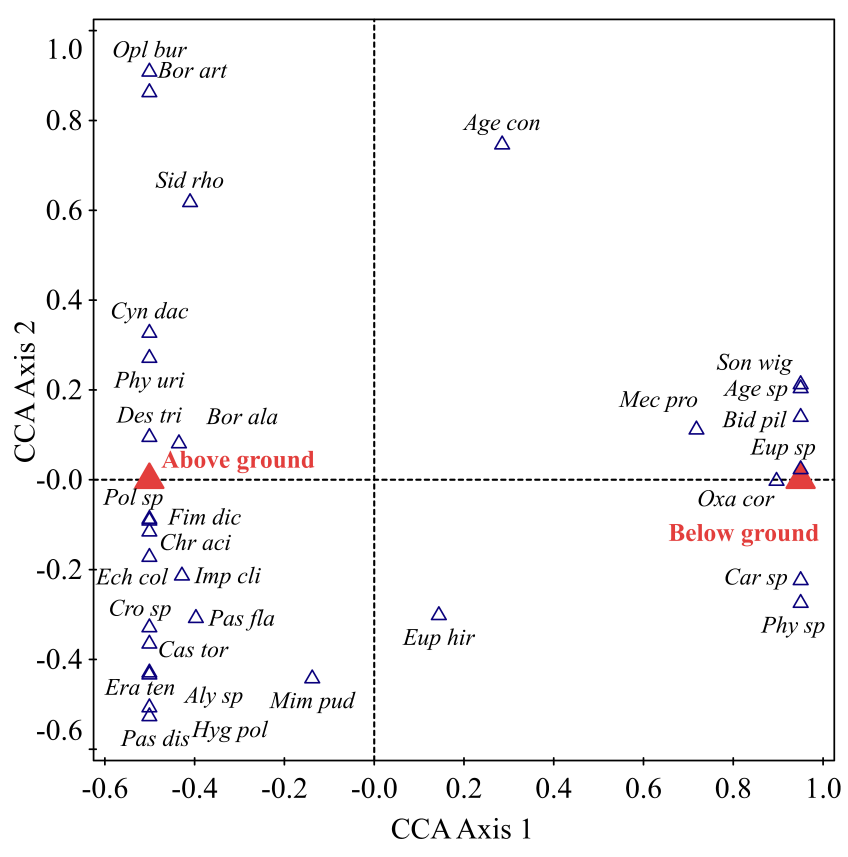

Fig. 3 Species composition of above ground flora and soil seedbank in plots with high Parthenium invasion. First Canonical Correspondence Analysis (CCA) axis explained $18.79 \%$ variation and the second axis $6.96 \%$. Full names of the species are in Additional file 1 (Tables S1 and S2).

density in both soil depths. However, it was 14 times higher $(p<0.001)$ in the soil from the top layer $(0-5 \mathrm{~cm} ; 8624 \pm$ 6509 seeds $\left./ \mathrm{m}^{2}\right)$ than in the deeper layer $(5-10 \mathrm{~cm} ; 620 \pm$ 818 seeds $\left./ \mathrm{m}^{2}\right)$. The overall soil $(0-10 \mathrm{~cm}$ depth) seedbank density of Parthenium was $9244 \pm 6535$ seeds $/ \mathrm{m}^{2}$, contributing $68 \%$ to the total germinable soil seedbank in the top layer $(0-5 \mathrm{~cm})$ and $38 \%$ in the deeper layer $(5-10 \mathrm{~cm})$. On considering the entire depth of the soil $(0-10 \mathrm{~cm})$, Parthenium contributed to $65 \%$ to the total soil seedbank.

\section{Discussion}

\section{Impacts of Parthenium on species composition and richness}

Our study showed that Parthenium invasion has modified the species composition without significant impact on species richness. Plots with different levels of Parthenium invasion showed variation of species composition. Previous studies have also shown that invasive species including Parthenium may have little effect on species diversity but have significant effects on the species composition (Hejda and Pysek 2006; Martin 1999; Timsina et al. 2011). Fiveyear long study conducted in the same area of the present study also showed a significant shift in species composition with increase in Parthenium abundance over the time (Rokaya et al. 2020). Such compositional change in community due to Parthenium invasion may result in disappearance of native species (Ayele et al. 2013). Change in species composition may be driven by species and population traits of 
Parthenium which are responsible for its high invasiveness. These traits that contribute to high invasiveness of this plant are high canopy cover and density, prolific seed production, high nutrient use efficiency, and allelopathic potential (Bajwa et al. 2016; Rokaya et al. 2020). Some resident species growing in the invaded sites are more sensitive than others to the allelopathic potential of Parthenium (Belgeri and Adkins 2015; Paudel and Shrestha 2019). Sensitive species may be displaced by Parthenium easily while the resistant species may persist in or recolonize the Parthenium invaded micro-habitat. Additionally, change in species composition may also be driven by a change in disturbance regime at micro-habitat level due to Parthenium invasion which is not uniform spatially. For example, grazing intensity is likely to be low at highly invaded plots because livestock tends to avoid such micro-habitat due to low availability of forage (Rokaya et al. 2020; Shrestha et al. 2015; Timsina et al. 2011).

There was no significant difference in species richness among plots of different levels of Parthenium invasion. This result contradicts with other studies, which suggested that invasive species have negative effects on species richness (Bimová et al. 2004; Dunbar and Facelli 1999; Kohli et al. 2004). Kohli et al. (2004) reported a decline in species richness from 25 to 12 from Parthenium non-invaded site to high invaded site in lower Himalaya (India). Rokaya et al. (2020) found sharp decline in plant species richness from 2009 to 2012 suggesting adverse effect of increasing Parthenium invasion on many native species. They also reported a significant decline in species richness with increase in Parthenium height. However, in grazing land the species richness may increase at the early stage of invasion (i.e., before the Parthenium forms pure dense stand by replacing other species) due to grazing exclusion and shift of dominance (Timsina et al. 2011). Timsina et al. (2011) reported lower species diversity in the Parthenium non-invaded plots than in intermediately invaded plots. In our study, lack of significant difference in species richness between plots of high and low levels of Parthenium invasion might also be the outcome of positive impact of defoliation of Parthenium by beetle Zygogramma bicolorata, a biological control agent, or shorter duration of research time period than Rokaya et al. (2020). During the sampling, we observed $>60 \%$ of leaves of Parthenium damaged by the beetle, allowing adequate light to reach the ground surface. That environment might be less hostile than in the stands with intact leaves. In absence of such control measure, and under intense livestock grazing, Parthenium can competitively displace pasture species, reduce pasture vigor and seed set leading to habitat and ecosystem change (Evans 1997; O’Donnell and Adkins 2005; Shabbir and Bajwa 2006). The current and the previous studies discussed above have suggested that the ecological impacts of Parthenium invasion on species composition and diversity can be modified by disturbance regime shift (e.g., livestock grazing) and control measures such as the presence of biological control agents.

\section{Comparison between above ground and belowground flora}

There was very low species similarity (Jaccard's Similarity Index being 19\% and Sorensen's similarity index being $32 \%$ ) between standing flora (above ground) and soil seedbank (below ground) flora. Our result is in line with Looney and Gibson (1995) who showed the value for Jaccard's Similarity Index to be $36 \%$ between standing flora and soil seedbank in coastal barrier island of Florida, the USA. We found significant difference in the species composition of above ground flora and soil seedbank. Such differences are also reported earlier (e.g., Ayele et al. 2013; Török et al. 2009). Ayele et al. (2013) compared the vegetation composition between the standing flora and soil seedbank flora in the plots with different levels of Parthenium invasion and found the highest similarity in the Parthenium non-invaded plots and the lowest similarity in the plots with high Parthenium invasion, indicating the impact of Parthenium invasion. High degree of allelopathy might have suppressed the germination and growth of the native species in highly invaded plots (Bajwa et al. 2016). Since Parthenium invasion has impacts on species composition, change in soil seedbank composition can be correlated with the change in species composition in the following year.

Beside the allelopathic effect of Parthenium, there are various reasons for affecting soil seedbank species composition. First, annual species tends to dominate soil seedbank, and perennial species to the aboveground vegetation in Parthenium invaded sites (Ayele et al. 2013). Second, loss of seeds due to predation and loss of seed viability also affect the plant species composition of soil seedbank (Schafer and Chilcote, 1970; Wilson et al., 1993). Third, mostly the annual forbs show high seed dormancy, low seed predation, and high persistence in soil seedbank which favor the germination of most of their seeds in the coming season. Whereas, in case of perennial grasses, most of the seeds get lost before germination due the low level of seed dormancy and high vulnerability to predators. Buried seeds might also fail to emerge due to death as a result of physiological aging and seed decomposition (Baskin and Baskin 2014). Fourth, non-dormant seeds of some species may reenter dormancy if environmental conditions are unfavourable for germination thereby affecting the seedbank dynamics (Baskin and Baskin 2014). Thus, the soil seedbank dynamics could also be the reason for the low similarity between aboveground and belowground flora in the present study area. 


\section{Contribution of Parthenium weed on soil seedbank}

Parthenium had the highest value of germinable soil seedbank density among all the germinated species recorded in the soil samples collected from the present study site. Parthenium alone contributed about $65 \%$ to the total germinable soil seedbank density in soil samples from $0-10$ $\mathrm{cm}$ depth. Dominance of Parthenium in soil seedbank has been also reported in other parts of the world. For example, in Moolayember Creek, Australia, Parthenium accounted for $65 \%-87 \%$ of the total soil seedbank (Navie et al. 2004). Similarly, in southeastern Ethiopian rangeland, Parthenium contributed up to $84 \%$ to total soil bank under the high weed invasion level (Ayele et al. 2013). Greater contribution of Parthenium in the soil seedbank might be due to its prolific seed production, persistence nature of soil seedbank, high viability of buried seeds, low seed predation, and innate dormancy mechanism of its seeds (Baskin and Baskin 2014; Haseler 1976; Joshi 1991). Parthenium is a short-lived weed possessing long lived seeds often with secondary dormancy mechanism (Rice 1989). Germination inhibitors (parthenin and phenolic acids) present in the accessory structures and seed coat of Parthenium seeds act as autotoxins that temporarily prevent the germination of nearby Parthenium seeds if their density is sufficiently high (Picman and Picman 1984) thereby decreasing the seed losses because of germination. Parthenin also increases seed survival by discouraging the decay (Ganeshan and Jayachandra 1993; Rice 1984) or predation (Ahmed and Bhattacharya 1991) of seeds.

A typical mature plant of Parthenium can produce about 15,000 seeds (Haseler 1976) forming enormous soil seedbank. Accumulation of seeds to the persistent soil seedbank of Parthenium leads to the increase in the size of its soil seedbank (Adkins and Shabbir 2014; Navie et al. 1998). The average seed density of Parthenium was 9244 seeds $/ \mathrm{m}^{2}$ for $0-10 \mathrm{~cm}$ soil depth in the present study site. Previous studies have reported a range of soil seedbank density of Parthenium: 20600 to 44600 seeds $/ \mathrm{m}^{2}$ at the Moolayember Creek, Australia (Navie et al. 2004); 300 seeds $/ \mathrm{m}^{2}$ at very low Parthenium invaded sites and 1880 seeds $/ \mathrm{m}^{2}$ at high Parthenium invaded sites in Ethiopia (Ayele et al. 2013). From the current study area, Rokaya et al. (2020) reported Parthenium soil seedbank at 5000 to $9000 \mathrm{seed} / \mathrm{m}^{2}$ over the period of five years. Relatively smaller size of soil seedbank densities of Parthenium in our study site compared to Australian sites might be because of its recent invasion in Nepal which is not enough to contribute large soil seedbank as that of Australia. Low soil seedbank may also be attributed to the activities of biological control agents (e.g., Zygogramma bicolorata in the study site) (Dhileepan et al. 2018) but it requires further investigations in the present study site. The variation in soil seedbank is also attributed to the climatic factors and soil conditions which vary spatially as well as temporally (Baskin and Baskin 2014).
Most of the germinable seeds of Parthenium concentrated at the top layer $(0-5 \mathrm{~cm})$ of the soil which was supported by other seedbank studies (Fenner 2000; Török et al. 2009). More than $70 \%$ of the seeds buried below $5 \mathrm{~cm}$ soil depth remain viable for 2 years (Adkins and Shabbir 2014). Greater percentage of seedling emergence from the soil samples of top layer showed the higher accumulation of seeds to surface soil. The deep burial of seed is less likely in the area where there is less soil disturbance. The present study site being the grazing land, soil disturbance in this case might be just due to trampling effect of grazing animals which might lead to the shallow burial of the seeds (Baskin and Baskin 2014). Deep burial of seed in such case requires very long time. The lesser percentage of germinable seeds from the deeper layer could be also related with its invasion history which is not very long in the sampling site.

\section{Conclusions}

In a grassland subjected to livestock grazing, we showed that Parthenium invasion significantly altered species composition of the aboveground vegetation without significantly affecting the species richness. There was a large difference in species composition between aboveground vegetation and soil seedbank; and Parthenium accounted > $2 / 3$ rd of the total soil seedbank density. The present results suggest that multiple parameters have to be considered to fully understand the ecological impacts of the invasive alien plant species and to inform management and policy decisions. High dominance by Parthenium weed in soil seedbank is particularly challenging because of its ability to remain viable in soil for a prolonged period. The results suggest the need of monitoring the soil seedbank dynamics while managing Parthenium weed. Control measures such as the use of biological control agents can reduce seed output and deplete soil seedbank over the time which may eventually give way to native species for re-colonization of the habitats. Given that a biological control agent Zygogramma bicolorata is already present in the study area, impacts of this agent on soil seedbank dynamics and restoration of native plant communities can be an important area for future research.

\section{Supplementary information}

Supplementary information accompanies this paper at https://doi.org/10.5141/jee.21.00083.

Additional file 1: Table S1. List of plant species recorded in above ground vegetation in the sample plots. Table S2. List of plant species at two different soil depths $(0-5 \mathrm{~cm}$ and 5-10 $\mathrm{cm}$ ) recorded during the soil seedbank study. 


\author{
Abbreviations \\ CCA: Canonical Correspondence Analysis \\ KATH: National Herbarium and Plant Laboratories, Nepal \\ SPSS: Statistical Package for Social Sciences \\ TUCH: Tribhuvan University Central Herbarium, Nepal
}

\section{Acknowledgements}

We are thankful to Ambika Paudel for help in field data collection and laboratory works, and Mahesh Bisht for preparing map of the study area. We are also thankful to Tribhuvan University Central Herbarium (TUCH) and National Herbarium and Plant Laboratories (KATH) for their permission to examine herbarium specimens for plant identification.

\section{Authors' contributions}

BBS conceptualized the research and did experimental design. JKC and BBS collected field and laboratory data. MBR and JKC analyzed data. JKC prepared first draft of the manuscript. BBS, MBR and JKC revised and finalized the manuscript.

\section{Authors' information}

JKC, MSc, is an Assistant Professor at Botany Department, Trichandra Multiple Campus, Tribhuvan University, Kathmandu, Nepal. She has completed her two years master's degree in Botany (specialization is ecology). She has research interests in invasion ecology, soil seedbank study, plant allelopathy, and plant ecophysiology.

MBR, PhD, is a research fellow at Czech Academy of Sciences (Institute of Botany and Global Change Research Institute). His research interests are on biological invasions, economically important plants and spatial ecology mainly along elevational gradients in Himalayan region.

BBS, PhD, is an Associate Professor at the Central Department of Botany, Tribhuvan University, Kathmandu, Nepal, with research interests on biological invasions, forest ecology, and plant adaptation along environmental gradients in mountains. He is currently involved as Lead Author in thematic Assessment on Invasive Alien Species which is being commissioned by the Intergovernmental Science-Policy Platform for Biodiversity and Ecosystem Services (IP$\mathrm{BES})$.

\section{Funding}

Field and laboratory works were supported by a grant from Nepal Academy of Science and Technology (NAST) to BBS. Partial financial support was also received by JKC from Cornell Nepal Student Programm (CNSP), Kirtipur, Nepal. MBR is partly supported by long-term research development project No. RVO 67985939 of the Czech Academy of Sciences and institutional support for science and research of the Ministry of Education, Youth and Sports of the Czech Republic.

\section{Availability of data and materials}

The datasets supporting the conclusions of this article are included within the article (and its additional files).

\section{Ethics approval and consent to participate \\ Not applicable}

\section{Consent for publication \\ Not applicable}

\section{Competing interests}

The authors declare that they have no competing interests.

\section{References}

Adkins S, Shabbir A. Biology, ecology and management of the invasive parthenium weed (Parthenium hysterophorus L.). Pest Manag Sci. 2014;70(7):1023-9. https://doi.org/10.1002/ps.3708.

Ahmed SR, Bhattacharya AK. Growth inhibitory effect of some plants for Spilosoma obliqua Walker. Indian J Entomol. 1991;53(3):453-74.

Allan S, Shi B, Adkins SW. Impact of parthenium weed on human and animal health. In: Adkins S, Shabbir A, Dhileepan K, editors. Parthenium weed: biology, ecology and management. Oxfordshire: $\mathrm{CAB}$ International; 2019. p. 105-30.

Ayele S, Nigatu L, Tana T, Adkins SW. Impact of parthenium weed (Parthenium hysterophorus L.) on the above-ground and soil seed bank communities of rangelands in Southeast Ethiopia. Int Res J Agric Sci Soil Sci. 2013;3(7):262-74.

Bajwa AA, Chauhan BS, Farooq M, Shabbir A, Adkins SW. What do we really know about alien plant invasion? A review of the invasion mechanism of one of the world's worst weeds. Planta. 2016;244(1): 39-57. https://doi.org/10.1007/s00425-016-2510-x.

Bajwa AA, Farooq M, Nawaz A, Yadav L, Chauhan BS, Adkins S. Impact of invasive plant species on the livelihoods of farming households: evidence from Parthenium hysterophorus invasion in rural Punjab, Pakistan. Biol Invasions. 2019;21(11):3285-304. https://doi. org/10.1007/s10530-019-02047-0.

Baskin CC, Baskin JM. Seeds: ecology, biogeography, and evolution of dormancy and germination. 2nd ed. Amsterdam: Academic Press; 2014.

Belgeri A, Adkins SW. Allelopathic potential of invasive parthenium weed (Parthenium hysterophorus L.) seedlings on grassland species in Australia. Allelopath J. 2015;36(1):1-14.

Bímová K, Mandák B, Kašparová I. How does Reynoutria invasion fit the various theories of invasibility? J Veg Sci. 2004;15:495-504. https://doi.org/10.1111/j.1654-1103.2004.tb02288.x.

Butler JE. Longevity of Parthenium hysterophorus L. seed in the soil. Aust weeds. 2013;3(1):6.

Chhogyel N, Kumar L, Bajgai Y. Invasion status and impacts of parthenium weed (Parthenium hysterophorus) in West-Central region of Bhutan. Biol Invasions. 2021;23:2763-79. https://doi.org/10.1007/ s10530-021-02534-3.

Cilliers SS, Williams NSG, Barnard FJ. Patterns of exotic plant invasions in fragmented urban and rural grasslands across continents. Landsc Ecol. 2008;23(10):1243-56. https://doi.org/10.1007/s10980-0089295-7.

Coffin DP, Lauenroth WK. Spatial and temporal variation in the seed 
bank of a semiarid grassland. Am J Bot. 1989;76(1):53-8. https://doi. org/10.1002/j.1537-2197.1989.tb11284.x.

Dhileepan K, Callander J, Shi B, Osunkoya OO. Biological control of parthenium (Parthenium hysterophorus): the Australian experience. Biocon Sci Technol. 2018;28(10):970-88. https://doi.org/10.1080/09 583157.2018.1525486.

Dunbar KR, Facelli JM. The impact of a novel invasive species, Orbea variegata (African carrion flower), on the chenopod shrublands of South Australia. J Arid Environ. 1999;41(1):37-48. https://doi. org/10.1006/jare.1998.0471.

Evans HC. Parthenium hysterophorus: a review of its weed status and the possibilities for biological control. Biocont News Inf. 1997;18(3): $89 \mathrm{~N}-98 \mathrm{~N}$.

Fenner M. Seeds: the ecology of regeneration in plant communities. 2nd ed. Wallingford: CABI Publishing; 2000.

Ganeshan G, Jayachandra. Antifungal activity of parthenin. Indian Phytopathol. 1993;46(2):193-4.

Gupta S, Narayan R. Species diversity in four contrasting sites in a peri-urban area in Indian dry tropics. Trop Ecol. 2006;47(2):229-41.

Haseler WH. Parthenium hysterophorus L. in Australia. PANS. 1976;22(4):515-7. https://doi.org/10.1080/09670877609414342.

Hejda M, Pyšek P. What is the impact of Impatiens glandulifera on species diversity of invaded riparian vegetation? Biol Conserv. 2006; 132(2):143-52. https://doi.org/10.1016/j.biocon.2006.03.025.

Hejda M, Hanzelka J, Kadlec T, Štrobl M, Pyšek P, Reif J. Impacts of an invasive tree across trophic levels: species richness, community composition and resident species' traits. Divers Distrib. 2017;23(9):9971007. https://doi.org/10.1111/ddi.12596.

Joshi S. Biocontrol of Parthenium hysterophorus L. Crop Prot. 1991; 10(6):429-31. https://doi.org/10.1016/S0261-2194(91)80129-4.

Kohli RK, Dogra KS, Batish DR, Singh HP. Impact of invasive plants on the structure and composition of natural vegetation of Northwestern Indian Himalayas. Weed Technol. 2004;18(sp1):1296-300. https:// doi.org/10.1614/0890-037X(2004)018[1296:IOIPOT]2.0.CO;2.

Looney PB, Gibson DJ. The relationship between the soil seed bank and above-ground vegetation of a coastal barrier island. J Veg Sci. 1995;6(6):825-36. https://doi.org/10.2307/3236396.

Maharjan S, Shrestha BB, Devkota A, Muniappan R, Jha PK. Temporal and spatial patterns of research on a globally significant invasive weed Parthenium hysterophorus L.: a bibliographic review. Crop Prot. 2020;135:104832. https://doi.org/10.1016/j.cropro.2019.05.026.

Mainali KP, Warren DL, Dhileepan K, McConnachie A, Strathie L, Hassan G, et al. Projecting future expansion of invasive species: comparing and improving methodologies for species distribution modeling. Glob Chang Biol. 2015;21(12):4464-80. https://doi.org/10.1111/ gcb.13038.

Mao R, Shabbir A, Adkins S. Parthenium hysterophorus: a tale of global invasion over two centuries, spread and prevention measures. J Environ Manage. 2021;279:111751. https://doi.org/10.1016/j.jenvman. 2020.111751.

Marahatta S, Dangol BS, Gurung GB. Temporal and spatial variability of climate change over Nepal, 1976-2005. Kathmandu: Practical Action Nepal Office; 2009.

Martin PH. Norway maple (Acer platanoides) invasion of a natural forest stand: understory consequence and regeneration pattern. Biol Invasions. 1999;1(2-3):215-22. https://doi.org/10.1023/A:1010084421858.

Milugo TK, Tchouassi DP, Kavishe RA, Dinglasan RR, Torto B. Root exudate chemical cues of an invasive plant modulate oviposition behavior and survivorship of a malaria mosquito vector. Sci Rep. 2021;11(1):14785. https://doi.org/10.1038/s41598-021-94043-5.

Mollot G, Pantel JH, Romanuk TN. The effects of invasive species on the decline in species richness: a global meta-analysis. In: Bohan DA, Dumbrell AJ, Massol F, editors. Advances in ecological research. London: Academic Press; 2017. p. 61-83. https://doi.org/10.1016/ bs.aecr.2016.10.002.

Navie SC, McFadyen RE, Panetta FD, Adkins SW. The biology of Australian weeds. 27. Parthenium hysterophorus L. Plant Prot Q. 1996; 11(2):76-88.

Navie SC, Panetta FD, McFadyen RE, Adkins SW. Behaviour of buried and surface-sown seeds of Parthenium hysterophorus. Weed Res. 1998;38(5):335-41. https://doi.org/10.1046/j.1365-3180.1998.00104. $\mathrm{x}$.

Navie SC, Panetta FD, McFadyen RE, Adkins SW. Germinable soil seedbanks of central Queensland rangelands invaded by the exotic weed Parthenium hysterophorus L.. Weed Biol Manag. 2004;4(3):154-67. https://doi.org/10.1111/j.1445-6664.2004.00132.x.

O'Donnell C, Adkins SW. Management of parthenium weed through competitive displacement with beneficial plants. Weed Biol Manag. 2005;5(2):77-9. https://doi.org/10.1111/j.1445-6664.2005.00160.x.

Paudel A, Shrestha BB. Germination response of herbaceous plant species to aqueous extracts of invasive alien weed Parthenium hysterophorus. Bot Orient J Plant Sci. 2019;13:1-12.

Picman J, Picman AK. Autotoxicity in Parthenium hysterophorus and its possible role in control of germination. Biochem Syst Ecol. 1984;12(3):287-92. https://doi.org/10.1016/0305-1978(84)90051-6.

Rice EL. Allelopathy. 2nd ed. Orlando: Academic Press; 1984.

Rice KJ. Impacts of seed banks on grassland community structure and population dynamics. In: Leck MA, Parker VT, Simpson RL, editors. Ecology of soil seed banks. San Diego: Academic Press; 1989. p. 211-30.

Rokaya MB, Khatri-Chettri J, Ghimire SR, Shrestha BB. Vegetation and soil seedbank dynamics in Parthenium hysterophorus L. invaded subtropical grassland in Nepal. Trop Ecol. 2020;61:238-47. https:// doi.org/10.1007/s42965-020-00085-7.

Roskov Y, Ower G, Orrell T, Nicolson D, Bailly N, Kirk PM, et al. Species 2000 \& ITIS Catalogue of Life, 2019 Annual Checklist. In: Plant List. Species 2000. 2019. https://www.catalogueoflife.org/annual-checklist/2019. Accessed 17 Jul 2019.

Schafer DE, Chilcote DO. Factors influencing persistence and depletion in buried seed populations. II. The effects of soil temperature and moisture. Crop Sci. 1970;10(4):342-5. https://doi.org/10.2135/cropsci1970.0011183X001000040007x.

Seastedt TR, Pyšek P. Mechanisms of plant invasions of North American and European grasslands. Annu Rev Ecol Evol Syst. 2011;42:133-53. https://doi.org/10.1146/annurev-ecolsys-102710-145057.

Shabbir A, Bajwa R. Distribution of parthenium weed (Parthenium hysterophorus L.), an alien invasive weed species threatening the biodiversity of Islamabad. Weed Biol Manag. 2006;6(2):89-95. https://doi. 
org/10.1111/j.1445-6664.2006.00202.x.

Shrestha BB, Pokhrel K, Paudel N, Poudel S, Shabbir A, Adkins SW. Distribution of Parthenium hysterophorus and one of its biological control agents (Coleoptera: Zygogramma bicolorata) in Nepal. Weed Res. 2019a;59(6):467-78. https://doi.org/10.1111/wre.12384.

Shrestha BB, Shrestha UB, Sharma KP, Thapa-Parajuli RB, Devkota A, Siwakoti M. Community perception and prioritization of invasive alien plants in Chitwan-Annapurna Landscape, Nepal. J Environ Manage. 2019b;229:38-47. https://doi.org/10.1016/j.jenvman.2018.06.034.

Shrestha BB, Shabbir A, Adkins SW. Parthenium hysterophorus in Nepal: a review of its weed status and possibilities for management. Weed Res. 2015;55(2):132-44. https://doi.org/10.1111/wre.12133.

Simpson RL, Leck MA, Parker VT. Seed banks: general concepts and methodological issues. In: Leck MA, Parker VT, Simpson RL, editors. Ecology of soil seed banks. San Diego: Academic Press; 1989. p. 3-8.

Siwakoti M, Varma SK. Plant diversity of Eastern Nepal: flora of plains of Eastern Nepal. Dehra Dun: Bishen Singh Mahendra Pal Singh; 1999.

Šmilauer P, Lepš J. Multivariate analysis of ecological data using CANOCO. 2nd ed. New York: Cambridge University Press; 2014.

Tamado T, Milberg P. Weed flora in arable fields of eastern Ethiopia with emphasis on the occurrence of Parthenium hysterophorus. Weed Res. 2000;40(6):507-21. https://doi.org/10.1046/j.1365-3180.2000.00208. $\mathrm{x}$.

ter Braak CJF, Smilauer P. Canoco 5, Windows release (5.04). Biometris. The Netherlands and Czech Republic: Plant Research International; 2012.

Timsina B, Shrestha BB, Rokaya MB, Münzbergová Z. Impact of Parthenium hysterophorus $\mathrm{L}$. invasion on plant species composition and soil properties of grassland communities in Nepal. Flora. 2011; 206(3):233-40. https://doi.org/10.1016/j.flora.2010.09.004.

Török P, Matus G, Papp M, Tóthmérész B. Seed bank and vegetation development of sandy grasslands after goose breeding. Folia Geobot. 2009;44:31-46. https://doi.org/10.1007/s12224-009-9027-z.

Upreti BN. An overview of the stratigraphy and tectonics of the Nepal Himalaya. J Asian Earth Sci. 1999;17(5-6):577-606. https://doi. org/10.1016/S1367-9120(99)00047-4.

Wilson SD, Moore DR, Keddy PA. Relationships of marsh seed banks to vegetation patterns along environmental gradients. Freshw Biol. 1993; 29(3):361-70. https://doi.org/10.1111/j.1365-2427.1993.tb00770.x.

Zobel DB, Jha PK, Behan MJ, Yadav UKR. A practical manual for ecology. Kathmandu: Ratna Book Distributors; 1987. 